\title{
Copper-Catalyzed Arylation and Alkenylation of Polyfluoroarene C-H Bonds
}

\author{
Hien-Quang Do and Olafs Daugulis ${ }^{*}$ \\ Department of Chemistry, University of Houston, Houston, TX 77204-5003
}

\section{Abstract}



An efficient, copper-catalyzed method for the arylation, alkenylation, and benzylation of polyfluoroarenes has been developed. Arenes containing two or more fluorine substituents on the aromatic ring can be efficiently functionalized. The best results are obtained by using a combination of copper iodide catalyst, phenanthroline ligand, aryl bromide or aryl iodide coupling partner and DMF or DMF/xylene mixed solvent.

Many directing-group containing arenes can now be arylated or alkylated under palladium, rhodium, or ruthenium catalysis. ${ }^{1}$ Even arenes lacking traditional directing groups can be functionalized representing the most atom-efficient method for creation of aryl-aryl bonds. ${ }^{2}$ However, in this case, regioselectivity issues often are unsolved. An exception can be found in recent elegant work by Fagnou who showed that polyfluorobenzene $\mathrm{C}-\mathrm{H}$ bonds can be arylated under palladium catalysis. ${ }^{3}$ The regioselectivity is imparted by the acidification of ortho-C-H bonds by fluorine substituents. While palladium catalysts can be replaced by copper in many coupling processes, ${ }^{4}$ use of this cheaper and more convenient alternative in $\mathrm{C}-\mathrm{H}$ activation reactions is not common. ${ }^{5}$ Fluorinated polyaryls are important in medicinal chemistry and direct methods for synthesis of these compounds may allow the development of more efficient pathways to pharmaceuticals. ${ }^{6} \mathrm{We}$ report here a general method for the copper-catalyzed arylation and alkenylation of polyfluorobenzene $\mathrm{C}-\mathrm{H}$ bonds.

We have recently shown that palladium catalyst can be replaced by copper in the arylation of electron-rich and electron-poor heterocycles. ${ }^{7}$ The reaction mechanism presumably includes a deprotonation of an acidic heterocycle followed by lithium/copper transmetallation and reaction of the organocopper species with aryl iodide. It is reasonable to assume that relatively acidic polyfluorobenzenes 8 can be arylated if a proper combination of base, solvent, and copper catalyst is used. A brief optimization of reaction conditions was carried out. For pentafluorobenzene arylation by aryl bromides, the best results were obtained in mixed DMF/ xylene solvent (1:1) and by employing phenanthroline ligand. Lower conversions were observed in DMF. Pentafluorobenzene can be arylated by both aryl bromides and aryl iodides. For other, less reactive substrates, the reaction with aryl iodide in DMF solvent results in higher yields. In most cases, potassium phosphate base affords the best results. Less acidic fluorobenzenes that contain fewer than three fluorines in the molecule can be arylated by employing lithium tert-butoxide base. The reaction scope with respect to aryl halide is 
presented in Table 1. Both electron-rich (Entries 1-5) and electron-poor (Entries 6-9) aryl halides are reactive. Functional groups, including ester (Entry 8) and cyano (Entry 9) are tolerated. Pyridyl (Entries 10 and 11) and electron-rich thienyl (Entry 12) bromides can be employed for the arylation. If a 5.7/1 E/Z mixture of $\beta$-bromostyrene was used in alkenylation of pentafluorobenzene, a 5.7/1 E/Z ratio of pentafluorostilbene was obtained (analysis of crude reaction mixture; $77 \% \mathrm{E}$ and $12 \% \mathrm{Z}$ isolated, Entry 13 ). Substantial steric hindrance is tolerated on the aryl halide (Entries 2 and 3). Mesitylation requires the use of aryl iodide to obtain high yield. Mesityl bromide afforded only $20 \%$ isolated yield of the coupling product.

Pentafluorobenzene is benzylated in fair yield (Entry 14). A side reaction between benzyl bromide and DMF solvent is responsible for the reduced yield. On a $10 \mathrm{mmol}$ scale yield is almost the same as on $1 \mathrm{mmol}$ scale ( $88 \%$ vs. $91 \%$, Entry 1$)$.

The scope with respect to fluoroarene is presented in Table 2. Two of the three tetrafluorobenzenes can be arylated in good yields (Entries 1-2). The arylation of 1,2,3,4tetrafluorobenzene affords only a low yield of the cross-coupling product (Entry 3). 1,3,5Trifluoro- and 1,3-difluorobenzenes are reactive; however, for the arylation of less acidic difluorobenzene a stronger base, $\mathrm{LiOtBu}$, is necessary. Fluorinated pyridines can also be arylated (Entries 6 and 7). Again, for the less fluorinated 3-fluoropyridine use of LiOtBu base is necessary. Fluorobenzene was unreactive under any conditions tried. As observed by Fagnou, ${ }^{3}$ the most acidic $\mathrm{C}-\mathrm{H}$ bonds, those flanked by two C-F bonds, are efficiently arylated.

It is known that pentafluorophenylcopper reacts with electrophiles, including aryl iodides, producing coupling products in high yield. ${ }^{9}$ It has also been reported that pentafluorobenzene reacts with aryl iodides in the presence of stoichiometric copper (I) oxide producing pentafluorobiaryls in moderate yields. ${ }^{10}$ In light of this, it is reasonable to assume that the catalytic reaction also proceeds by base-promoted formation of fluoroarylcopper followed by the reaction of the copper species with aryl halide affording the coupling product (Scheme 1). 11 If less acidic fluoroaryl is used, a stronger base is required to form the arylcopper species.

In conclusion, we have developed an efficient, copper-catalyzed method for the arylation, alkenylation, and benzylation of polyfluoroarenes. Arenes containing two or more fluorine substituents on the aromatic ring can be efficiently functionalized. The best results are obtained by using a combination of copper iodide catalyst, phenanthroline ligand, aryl bromide or aryl iodide coupling partner and DMF or DMF/xylene mixed solvent.

\section{Supplementary Material}

Refer to Web version on PubMed Central for supplementary material.

\section{Acknowledgements}

We thank the Welch Foundation (Grant No. E-1571) and National Institute of General Medical Sciences (Grant No. R01GM077635) for supporting this research.

\section{References}

1. (a) Oi S, Fukita S, Hirata N, Watanuki N, Miyano S, Inoue Y. Org Lett 2001;3:2579. [PubMed: 11483065] (b) Oi S, Ogino Y, Fukita S, Inoue Y. Org Lett 2002;4:1783. [PubMed: 12000298] (c) Ackermann L. Org Lett 2005;7:3123. [PubMed: 15987221] (d) Bedford RB, Coles SJ, Hursthouse MB, Limmert ME. Angew Chem, Int Ed 2003;42:112. (e) Kametani Y, Satoh T, Miura M, Nomura M. Tetrahedron Lett 2000;41:2655. (f) Kalyani D, Deprez NR, Desai LV, Sanford MS. J Am Chem Soc 2005;127:7330. [PubMed: 15898779] (g) Satoh T, Kawamura Y, Miura M, Nomura M. Angew Chem, Int Ed 1997;36:1740. (h) Chen X, Li JJ, Hao XS, Goodhue CE, Yu JQ. J Am Chem Soc 2006;128:78. [PubMed: 16390130] (i) Chen X, Goodhue CE, Yu JQ. J Am Chem Soc 2006;128:12634. [PubMed: 17002342] (j) Motti E, Faccini F, Ferrari I, Catellani M, Ferraccioli R. Org Lett 2006;8:3967. 
[PubMed: 16928050] (k) Lewis JC, Wiedemann SH, Bergman RG, Ellman JA. Org Lett 2004;6:35. [PubMed: 14703344] (1) Seregin IV, Gevorgyan V. Chem Soc Rev 2007;36:1173. [PubMed: 17576484] (m) Alberico D, Scott ME, Lautens M. Chem Rev 2007;107:174. [PubMed: 17212475]

2. (a) Fujita, K-i; Nonogawa, M.; Yamaguchi, R. Chem Commun 2004:1926. (b) Fuchita Y, Oka H, Okamura M. Inorg Chim Acta 1992;194:213. (c) Tani M, Sakaguchi S, Ishii Y. J Org Chem 2004;69:1221. [PubMed: 14961674] (d) Jintoku T, Fujiwara Y, Kawata I, Kawauchi T, Taniguchi H. J Organomet Chem 1990;385:297. (e) Ackerman LJ, Sadighi JP, Kurtz DM, Labinger JA, Bercaw JE. Organometallics 2003;22:3884. (f) Proch S, Kempe R. Angew Chem, Int Ed 2007;46:3135. (g) Hull KL, Sanford MS. J Am Chem Soc 2007;129:11904. [PubMed: 17845047]

3. (a) Lafrance M, Rowley CN, Woo TK, Fagnou K. J Am Chem Soc 2006;128:8754. [PubMed: 16819868] (b) Lafrance M, Shore D, Fagnou K. Org Lett 2006;8:5097. [PubMed: 17048852]

4. Copper-catalyzed C-N and C-C bond formation: (a) Klapars A, Antilla JC, Huang X, Buchwald SL. J Am Chem Soc 2001;123:7727. [PubMed: 11481007] (b) Allred GD, Liebeskind LS. J Am Chem Soc 1996;118:2748. (c) Thathagar MB, Beckers J, Rothenberg G. J Am Chem Soc 2002;124:11858. [PubMed: 12358523] (d) Ma D, Liu F. Chem Commun 2004:1934. (e) del Amo V, Dubbaka SR, Krasovskiy A, Knochel P. Angew Chem, Int Ed 2006;45:7838. (f) Campbell MJ, Johnson JS. Org Lett 2007;9:1521. [PubMed: 17362022] (g) Schaub T, Backes M, Radius U. J Am Chem Soc 2006;128:15964. [PubMed: 17165711]

5. (a) Chen X, Hao XS, Goodhue CE, Yu JQ. J Am Chem Soc 2006;128:6790. [PubMed: 16719450] (b) Uemura T, Imoto S, Chatani N. Chem Lett 2006;35:842. (c) Li Z, Li CJ. J Am Chem Soc 2005;127:6968. [PubMed: 15884937]

6. (a) Müller K, Faeh C, Diederich F. Science 2007;317:1881. [PubMed: 17901324] (b) Zahn A, Brotschi C, Leumann CJ. Chem-Eur J 2005;11:2125.

7. Do HQ, Daugulis O. J Am Chem Soc 2007;129:12404. [PubMed: 17887762]

8. (a) Streitweiser A Jr, Scannon PJ, Niemeyer HM. J Am Chem Soc 1972;94:7936. (b) Schlosser M. Angew Chem, Int Ed 1998;37:1496.

9. (a) Cairncross A, Sheppard WA. J Am Chem Soc 1968;90:2186. (b) Sheppard WA. J Am Chem Soc 1970;92:5419. (c) Jukes AE, Dua SS, Gilman H. J Organomet Chem 1970;24:791.

10. Ljusberg H, Wahren R. Acta Chem Scand 1973;27:2717.

11. Arylation of the mixture of pentafluorobenzene and 1,2,4,5-tetra-fluorobenzene under usual reaction conditions resulted in preferential arylation of pentafluorobenzene (2/1). Additionally, it was shown that base-promoted H/D exchange in polyfluoroarenes occurs with the same efficiency both in the presence or absence of CuI. See Supporting information for details. 


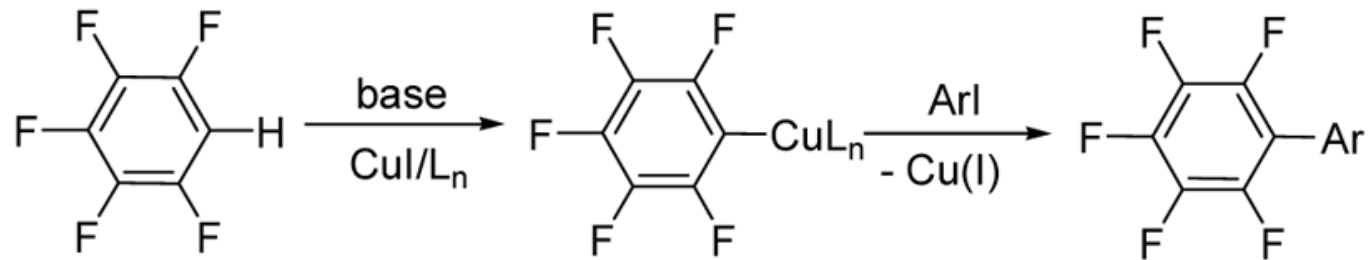

Scheme 1.

Mechanistic considerations. 
Table 1

Arylation scope with respect to halides ${ }^{a}$

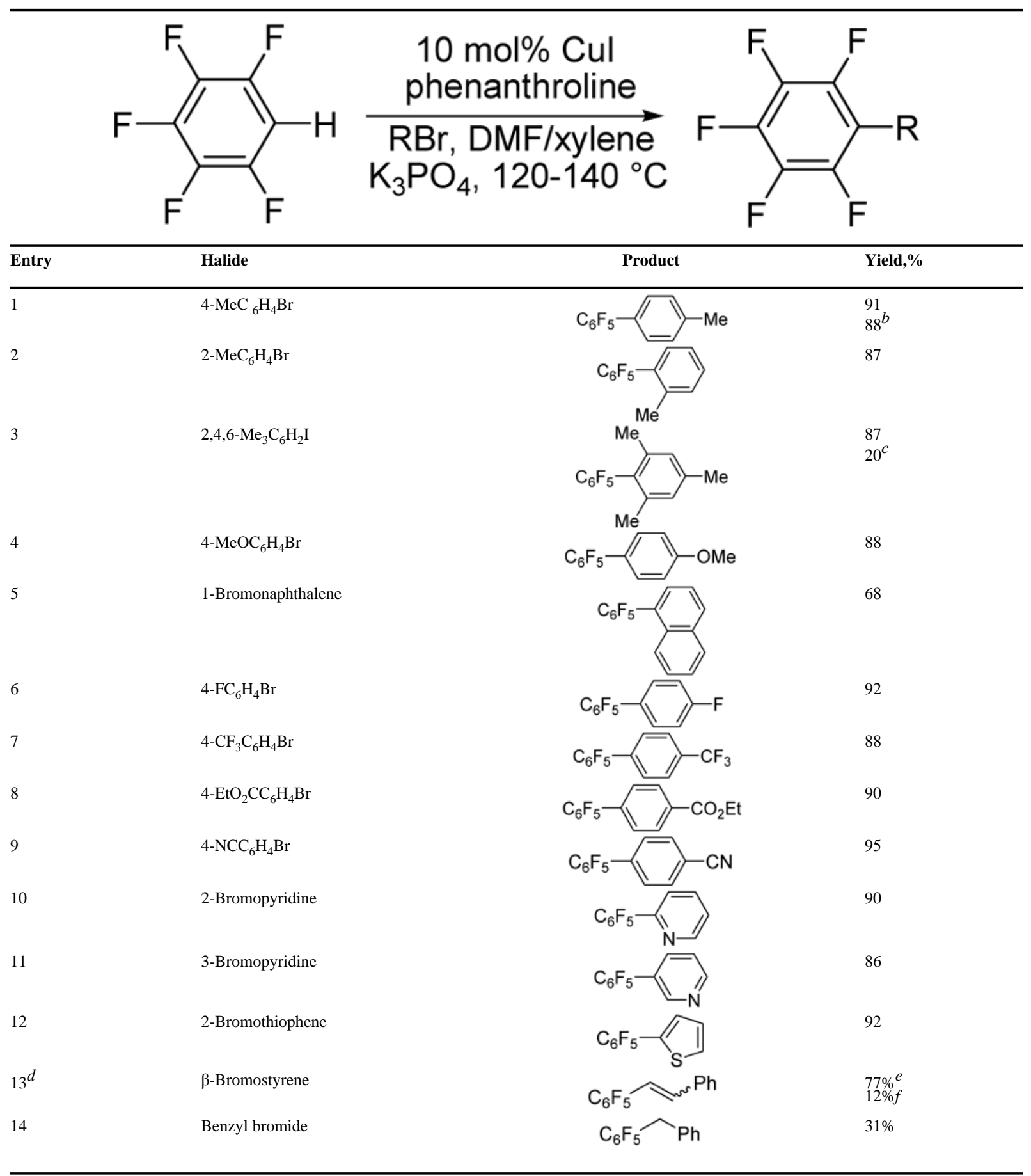

${ }^{a}$ Substrate (1.5 equiv), aryl halide (1 equiv), base (2 equiv). Yields are isolated yields

$b_{\text {Ten mmol scale reaction }}$

${ }^{c}$ Mesityl bromide used

$d_{\mathrm{E} / \mathrm{Z} \text { Mixture (5.7/1) of bromoalkene used }}$ 
${ }^{e}$ Yield of E-isomer.

$f_{\text {Yield of Z-isomer }}$ 
Table 2

Arylation scope with respect to fluoroarenes ${ }^{a}$



\footnotetext{
${ }^{a}$ Substrate (2-3 equiv), aryl halide (1 equiv), base (2-2.5 equiv). Yields are isolated yields

$b_{\text {Diarylation product (15\%) also isolated }}$

${ }^{c}$ Diarylation product (17\%) also isolated

$d_{\text {Lithium } t \text {-butoxide base }}$
} 